Article

\title{
Driving the European Green Deal in Turbulent Times
}

\author{
Mary Dobbs ${ }^{1}$, Viviane Gravey ${ }^{2, *}$ and Ludivine Petetin ${ }^{3}$ \\ ${ }^{1}$ Department of Law, Maynooth University, Ireland; E-Mail: mary.dobbs@mu.ie \\ 2 School of History, Anthropology, Philosophy and Politics, Queen's University Belfast, UK; E-Mail: v.gravey@qub.ac.uk \\ ${ }^{3}$ School of Law and Politics, Cardiff University, UK; E-Mail: petetinl@cardiff.ac.uk \\ * Corresponding author
}

Submitted: 30 March 2021 | Accepted: 14 June 2021 | Published: 30 September 2021

\begin{abstract}
The European Green Deal (EGD) is an ambitious strategy. However, significant events, incidents, and demands, from democratic backsliding in the EU to the Covid-19 pandemic, are causing the ground to shift underfoot. These events go beyond ordinary changes or even individual crises, cumulatively fuelling a "new normal" of turbulence for the EU, encompassing rapid, unpredictable changes. This turbulence can help and hinder policy design and implementation, requiring policy actors to think outside the box and beyond the status quo. This article investigates how the European Commission and other key actors can engage effectively with turbulence to ensure the successful delivery and implementation of the EGD. The first half of the article strengthens and adapts turbulent governance literature (Ansell \& Trondal, 2018). It delineates how turbulence differs from crisis; expands the forms of turbulence to include horizontal scalar and policy turbulence, as well as its transversal attribute; and shifts the focus to governing with turbulence rather than against turbulence. The second half undertakes an initial analysis of the EGD in light of turbulence and provides a springboard for further investigations within this thematic issue and beyond. It is apparent that the EGD is both responding and contributing to a varied landscape of turbulence. Policy actors must identify and understand the sources of turbulence-including their transversal nature and the potential for responses to increase turbulence-if they are to effectively govern with turbulence.
\end{abstract}

\section{Keywords}

crisis; environmental governance; environmental turbulence; European Green Deal; organisational turbulence; policy turbulence; scalar turbulence

Issue

This article is part of the issue "Climate Governance and the European Green Deal in Turbulent Times" edited by Claire Dupont (Ghent University, Belgium) and Diarmuid Torney (Dublin City University, Ireland).

(C) 2021 by the authors; licensee Cogitatio (Lisbon, Portugal). This article is licensed under a Creative Commons Attribution 4.0 International License (CC BY).

\section{Introduction}

The European Green Deal (EGD) has become the central tenet of the von der Leyen Commission, setting out a holistic approach towards the climate and biodiversity crises with policies ranging from agriculture and food to a circular economy. It is both an overarching set of priorities of the new European Commission (hereafter Commission)-a communication published in December 2019 as it took office (European Commission, 2019b) - and the ensuing legislative and administrative agenda of 47 key actions. These span seven substan- tive themes: climate ambition; clean, affordable, and secure energy; industrial strategy for a clean and circular economy; sustainable and smart mobility; greening the Common Agricultural Policy (CAP)/“Farm to Fork"; preserving and protecting biodiversity; and moving towards a zero-pollution ambition for a toxic free environment. To achieve this, the EGD promotes three procedural themes: mainstreaming sustainability in all EU policies, pushing for the EU to be a global leader and working together across levels, and policy areas for a European Climate Pact (European Commission, 2019a). Alongside its environmental ambition, it has a clear focus 
on "just transition," e.g., to avoid massive unemployment in carbon-intensive industries overnight (European Commission, 2019b). The EGD therefore appears to promote an inclusive vision of sustainability with emphasis on a "just transition" that would leave "no one behind" (European Commission, 2019b, p.16). It pushes boundaries and proposes major changes beyond what the EU has attempted previously, including the key ambition of making Europe the first carbon-neutral continent by 2050. However, the EU is seeking to achieve this not merely in the face of crises but in the context of significant turbulence (Oberthür et al., 2016).

This article draws upon Ansell and co-authors' understanding of turbulence, which they define as "interactions of events or demands that are highly variable, inconsistent, unexpected or unpredictable" (Ansell et al., 2016 , p. 3). They distinguish turbulence from crisis by drawing on notions of "shifting parameters," "intercurrence," and "temporal complexity" (Ansell \& Trondal, 2018 , p. 45). Shifting parameters-the idea that "the ground is in motion" (Ansell \& Trondal, 2018, p. 45)means turbulence aims not to capture the crisis response of stable political systems, but instead the "increasingly volatile context for complex problem-solving" (Ansell et al., 2020, p. 3). Intercurrence concerns "unexpected institutional entanglement" (Ansell \& Trondal, 2018, p. 45) which grows between normally independent levels and organisations when decision-makers try to respond to turbulence. These entanglements can be understood as "interplays" between institutions, "situations in which one institution affects the development or performance of another institution" (from the local to the global levels), ranging from "disruptive" to "synergetic" (Oberthür \& Stokke, 2011, p. 4). While interplays are common and often managed, the growing number of institutions and their fluctuating mandates can lead to unexpected entanglements. Finally, temporal complexity captures the way decision-makers are put under strain by different and competing time horizons (Ansell \& Trondal, 2018). When the three facets of shifting parameters, intercurrence, and temporal complexity combine, turbulence flourishes. The turbulence imbues the system, weaving its way through until it becomes the "new normal" or new landscape for political systems-to a similar extent that "rapid change and unpredictability in both the market and technology standards" is part of the business environment of many firms (Yun et al., 2019, p. 218). It is the point the UK has reached when delivering Brexita radical departure which destabilises policy, politics, and polity (Burns et al., 2019). It is also where the EU, which has faced repeated crises (Falkner, 2016; Rhinard, 2019), has now arrived-bringing both challenges and opportunities for the EGD and its ambitions.

This article addresses the question of how the Commission and other key actors can engage effectively with turbulence to ensure the successful delivery and implementation of the EGD, as an ambitious policy that arises in a turbulent landscape. It seeks to make both the- oretical and practical contributions. The article (1) teases out the features that distinguish turbulence from crisis. It then (2) develops an enhanced conceptual framework focused on turbulence, building on Ansell and coauthors' work. It outlines the need to govern with rather than against turbulence; categorises the different forms of turbulence; and discusses the need to foster transformative actions towards durable policies. This provides an analytical foundation for the remainder of this article and also for this thematic issue. The article then applies this framework to undertake a preliminary analysis of the EGD. It (3) maps the four categories of turbulence on to the EGD, before (4) highlighting potential pathways and key challenges in developing and implementing the EGD in the face of turbulence, with a focus on Covid-19 and greening the CAP. As highlighted throughout this thematic issue, the EGD and the steps to implement it have the potential to be transformative, but with numerous challenges and pitfalls to be addressed. Not only is the EGD arising in the context of turbulence, it can be understood as both a response to, and a contributor to, turbulence at the EU level. If policy actors are effectively to govern with turbulence and thereby ensure the successful delivery and implementation of the EGD, they must identify and understand the sources of turbulence-including their transversal nature and the potential for responses to increase turbulence.

\section{Differentiating Between Turbulence and Crisis}

The EU has lived through many crises-indeed, Monnet famously argued that "Europe will be forged in crises, and will be the sum of the solutions adopted for those crises" (Monnet, 1976, as cited in Guiso et al., 2014, p. 1). This affinity between the EU and crisis-and between EU scholarship and crisis-may lead to concept overstretching and thus the need to clearly define what is and is not a crisis. At the heart of the concept of crisis is the existence of ordinary, non-crisis time-a crisis is an acute, extreme event which may ultimately be resolved leading to another period of calm (Saurugger, 2014). However, in recent years the EU has been beset by a multitude of crises, what Falkner termed "a conglomerate of specific but interconnected crises" (2016, p. 220). This begs the question of when, if ever, the EU can return to normal-if even "normal" makes sense for an ever-changing polity (Laffan et al., 2000). A recent questioning of what normal in the EU context means is Rhinard's work on crisification (2019). He found a growing number of dedicated crisis-scanning and crisis-managing institutions leading to a new mode of crisis policymaking operating alongside normal policymaking. Rhinard's crisification outlines how at least part of the EU's apparatus always operates in "crisis mode," even though normal policymaking continues in other areas.

Conceptualising the EU as experiencing turbulence goes a step further. Ansell et al. (2020) differentiate between turbulence and routine-turbulence has 
long been considered the exception, not the norm, yet recently "the balance between the routine and the turbulent has shifted and we have been slow to catch up" (p. 3). This, we argue, is particularly true for the EU. We start from the premise that there is no returning to "normal" time in between times of "crisis." The balance has shifted so that the ever-changing turbulent context is the "new normal" (Ansell \& Trondal, 2018, p. 53), the new routine-turbulence is pervasive throughout the whole EU system (no policy area is isolated from its effects). While Rhinard (2019) focuses on the impact on EU decision-making with crisification, turbulence adopts a broader scope, considering the interplay with other policy areas and levels of governance. Furthermore, the conceptual shift to turbulence is also a normative shift, as crisis has negative connotations-"threaten[ing] the high-priority goals" (Saurugger, 2014, p. 181)-whereas turbulence may also be positive.

Crises may contribute to turbulence but the two concepts are distinct. A practical example may provide some clarity here. A once-off magnitude 8 earthquake, Pompeii-scale of volcanic eruption or resulting tsunami is a crisis for the affected populations and leads to emergency responses to survive that singular incident. However, a location that is subjected to repeated midlevel earthquakes or volcanic ash clouds, with occasional ones of greater intensity (including crisis-level ones), is subject to turbulence and requires a response that enables those affected to live with the turbulence, whether this be to change the structural design of buildings, what crops are grown (e.g., those with short lifecycles or benefiting from ash), or otherwise. Consequently, being able to identify sources of turbulence-and not only crises-and tailor appropriate responses is an essential part of the governance toolkit.

\section{A Framework for Turbulent Times}

As noted, turbulence entails a new normal that encompasses shifting parameters, intercurrence, and temporal complexity. Whilst traditional approaches to governance or decision-making may be effective in the doldrums or even for individual crises, a tailored framework is needed in the context of turbulence. To respond effectively to turbulence, policy actors need to be able to identify and understand (1) the over-arching goal of governance in the context of turbulence; (2) specific instances and sources of turbulence; and (3) suitable responses to the turbulence. Consequently, this section outlines a conceptual framework to achieve this analysis, building on and adapting the work of Ansell and co-authors to the EU context.

\subsection{Steering Through Turbulence: Governing With and not Against Turbulence?}

Turbulence generally does not prevent the functioning of decision-making or governance, but it does pose con- siderable challenges for policy actors. It raises questions such as how to achieve existing goals or ambitions in a new context, or indeed whether those goals themselves need to be adapted. Does one try to patch the existing systems and regimes, throw in the towel, or undertake a substantial overhaul? Is it a matter of addressing a single, temporary instance of turbulence or attempting to insulate and prepare for future occurrences? What mechanisms could be of help?

Ansell and Trondal (2018) outline four potential dilemmas that policy actors may be faced with in the context of turbulence: stability vs. change; anticipation vs. resilience; tight(er) coupling vs. decoupling; and integration vs. differentiation. Whilst the dilemmas are useful considerations for policy actors, they highlight a more fundamental issue for actors: whether to govern against or with turbulence.

Governing against turbulence is focused on fixing the symptoms of turbulence and bypassing it as much as possible, in order to focus on the original aims and objectives. The purpose is to identify and address specific issues as a sort of patch job in the short-term. It also hopefully creates some general stability and consistency initially, providing space and time to focus on the long-term. In contrast, governing with turbulence entails acknowledging we may not be able to fully understand or prepare for turbulence-that it will reoccur in a new formulation or form.

Overall, governing against turbulence may work in the short term (and may even be desirable to ensure some stability and achieve specific goals). But as turbulence is an ongoing, developing condition where indeed more unpredictable turbulent events may occur, the system becomes increasingly stressed and subject to pressures, breakdown, and ruptures. As such, a shift to governing with turbulence is essential. The purpose of governing with turbulence is to build in flexibility, dynamism, resilience, and enable policy actors to respond more effectively to changes and overall turbulence in the future. Consequently, even if initially policy actors seek to govern against turbulence, in the long-term only governance with turbulence can be viable. Building such capacity brings considerable challenges as highlighted in Section 3.3, but first the policy actors must be able to identify sources of turbulence.

\subsection{Sources of Turbulence}

Building on earlier work in administration studies (e.g., Cameron et al., 1987), Ansell et al. (2016) conceptualise three different forms of turbulence which matter from a governance perspective, each impacting on, and impacted by, public organisations and institutions: organisational, environmental, and scalar. Organisational turbulence deals with turbulence within organisations and institutions, such as major administrative reform, staff conflict, or turnover. At EU level, this would cover, for example, tensions within the Commission ranks 
following repeated administrative reforms over the last 20 years (Kassim et al., 2013), and for climate action especially, the creation of DG CLIMA in 2010 and further reorganisation under President Juncker (Bürgin, 2020). Environmental turbulence concerns contextual, external forms of turbulence, from the Covid-19 pandemic to the ongoing climate and biodiversity emergencies. Scalar turbulence is of particular importance to multi-level polities such as the EU. It concerns the impact that decisions at one level can have on another level. As Ansell and Trondal (2018) argue, "a 'good' solution at one level might be considered a 'bad' solution at another level" (p. 46). This turbulence covers both intended and unintended consequences of multi-level decisionmaking, exposing the interdependence and interplay of the different decision centres (Oberthür \& Stokke, 2011). Ansell and Trondal (2018) limit themselves to the above three forms of turbulence, yet these are arguably insufficient. In our study of the impact of Brexit on UK agricultural policies, we expand further the conceptual framework they set in four ways (Dobbs et al., 2021).

First, although Ansell and Trondal (2018) focus on vertical examples of scalar turbulence, the impacts can also be felt horizontally (Dobbs et al., 2021). This reflects broader notions of multilevel governance (Hooghe \& Marks, 2003) and institutional interplay (Oberthür \& Stokke, 2011). Here, early responses to Covid-19 in Europe where national governments each went their separate ways, undermining both an EU-wide response but also their neighbours' own responses, created a particularly acute example of both horizontal and vertical scalar turbulence (Dobbs, 2020). The different levels of EU competences across policy areas (or lack thereof) and the policy-cycle, alongside the sometimes-fraught relationships between "Brussels" and some member states, make scalar turbulence particularly likely.

Second, we identified the possibility of a new, fourth form of "policy turbulence." This entails where there is substantial policy conflict or incoherence, e.g., due to multiple related policies in conflict, a substantive policy gap, or potentially a new policy that is exceptionally innovative or overhauls the regime. In the case of Brexit and agriculture, this was primarily through the loss of the CAP.

Third, categorisation of turbulence is not fixed and depends on the focus of study. Thus, depending on what part of the system is studied, a different categorisation or mapping of turbulence may be done: A study on policy divergence at regional level may consider vertical scalar turbulence-how their decision-making is constrained by policy choices made at higher levels of governance without considering their needs-more important, while an analysis of state responses may be more concerned with horizontal turbulence and the impact of decisions made by their neighbours. Furthermore, in our Brexit and agriculture example, losing the CAP may be policy turbulence for agriculture stakeholders but considered as contributing more to a generic environmental turbulence for green groups.
Finally, while it is useful to identify different forms of turbulence, they are not independent from each other. Instead, turbulence can be transversal in nature (building on the interdependence between levels posited by Ansell \& Trondal, 2018). Thus, at the very least, resources spent responding to one form of turbulence are not available for responding to others, stretching administrative and political capacity. But more fundamentally, responding to one form of turbulence can worsen another, for example the UK hastening to "get Brexit done" and address environmental turbulence has come at the cost of higher organisational turbulence for businesses exporting to the EU and scalar turbulence, evidenced by growing distrust between Westminster and the devolved administrations of Scotland, Wales, and Northern Ireland (Dobbs et al., 2021).

\subsection{Transforming to Govern With Turbulence}

Upon identifying sources of turbulence, policy actors must then determine how to respond. In order to govern with turbulence, something truly transformative is necessary (Ansell et al., 2020, p. 2)-but what does transformative look like?

From a governance perspective, Ansell et al. (2020) put forward "robust governance" conceptualised as:

The ability of one or more decision-makers to uphold or realise a public agenda, function, or value in the face of the challenge and stress from turbulent events and processes through the flexible adaptation, agile modification, and pragmatic redirection of governance solutions. (p. 5; emphasis added)

The focus is on change, resilience, and dynamism. It also fundamentally centres on effectiveness, reflected in the idea that it is the "ability... to uphold or realize a public agenda, function or value," i.e., to deliver concrete change.

Alternatively, from a policy perspective this means developing policy that is "durable by design" (Jordan \& Moore, 2020), "that endures and is influential over a particularly long period of time" and that has "the capacity to ride out the inevitable political bumps in the road that lies ahead without diminishing their effectiveness" (Jordan \& Moore, 2020, p. 5). Thus, the aim is to develop policies able to "ride out" future sources of turbulence, as yet of indeterminate nature. Both "durable by design" policies and "robust governance" offer an ideal of nimble policies and governance arrangements that can weather turbulence while not losing sight of their original goal. In practice, this may be delivered with entirely innovative tools or simply repurposing existing tools from one regime to another. To this end, lessons can be learnt, for instance, from literature on managing "gridlock" (e.g., Klyza \& Sousa, 2013) and on "new environmental policy instruments" (Moore et al., 2021). But nimble policy and governance ideals may be hard to 
deliver in practice. While Ansell et al.'s (2020) concept of robust governance is underpinned by flexible adaptation, great care is needed as actors governing with turbulence also risk losing sight of the original goals, objectives, and values, with potential knock-on effects on the long-term governance structures and regimes.

Turbulence literature stresses the need to consider turbulence holistically (taking into account its pervasive, long-term nature, the multitude of sources of turbulence and their transversality), and develop responses to turbulence accordingly in order to avoid displacing the problem. But this is extremely difficult for policymakers to do in practice-as evidenced by Ansell et al.'s different dilemmas and the potential dealignment between values, policy agendas, and governance functions (Ansell et al., 2020; Ansell \& Trondal, 2018). This parallels with Rhinard's (2019) crisification, where he describes politicians being faced with "real choices with consequences" or even facing "tragic choices" in a time-pressured context of crises (p. 11)-turbulence does not necessarily necessitate the same rushed responses, but this does not mean they do not occur or that difficult choices do not arise. In practice, governments tend to prioritise responding to one form of turbulence over another, or prioritising, for example, agenda or functions over value. This may be due to downplaying certain forms of turbulence, a lack of tools to target different forms of turbulence simultaneously, or consciously choosing what is, at least in the short term, the lesser evil: to live and fight (another form of turbulence) another day.

\section{Mapping Green Deal Turbulence}

The EGD-both the communication and the overarching legislative and administrative agenda for the von der Leyen Commission-can be analysed as the Commission's attempt at responding to turbulence and developing a nimble policy, durable by design which would allow the EU to become the first carbon-neutral "continent" by 2050. But, as expected, the ground keeps shifting under EU decision-makers. In the process of delivering the EGD legislative commitments, the EU faces four interconnected forms of turbulence, with some pre-existing sources and some more recent like the Covid-19 pandemic. Furthermore, the EGD itself becomes a source of turbulence for other policy areas. How the EU, and the Commission in particular, navigates each of these will determine whether the EGD is successful or whether, like many EU long-term strategies from the Lisbon Strategy to the Sustainable Development Strategies, it fails to deliver and loses sight of its objectives (Steurer, 2021).

\subsection{Organisational Turbulence}

Organisational turbulence is exemplified by the appointment of the entire von der Leyen Commission in 2019, which faced multiple obstacles and was central to the EGD's creation. The election of the president of the Commission was not an easy task. The European Parliament (hereafter Parliament) shortlisted its preferred candidates but the European Council (hereafter Council) ignored its selection and the heads of government proposed their own nominee (Hennessy, 2019). Von der Leyen secured her current position by a narrow margin of nine votes in front of the Parliament (383 votes, where 374 were required). This weakened her position from the outset and could lead to difficulties in successfully passing legislation through the Parliament-including legislation central to furthering the EGD. Beyond the Commission, the decision by Viktor Orban to preventively take his party Fidesz out of the European People's Party within the Parliament (after the European People's Party finally changed its internal rules to make it easier to exclude Fidesz) is shifting the balance of power within the Parliament in uncertain directions (Votewatch Europe, 2021).

However, von der Leyen also contributed to organisational turbulence-at least temporarily-through two key election promises: first, to provide the Parliament with the right of initiative of legislation that would end the monopoly of the Commission and shift the balance of powers between the institutions; second, to proceed to full co-decision for the Parliament (and thus move away from unanimity and consensus) in the areas of climate, energy, social, and taxation policies. Such changes could enable Members of the Parliament to put forward proposals that push for an even greener EU agenda, reflecting the 2019 "green turn" or wave in the Parliament and the growing recognition by EU citizens of the importance of environmental matters. Although attitudes vary considerably across issues-e.g., with the greatest consensus on the significance of climate change, in contrast for instance with noise pollution - the majority of those surveyed by the Commission in 2017 considered that environmental protection was very important and 94\% considered it important (European Commission, 2017). As well as impacting upon the institutions' relationships, this could either support the EGD by providing it with greater democratic underpinnings or indicate that it is not ambitious enough.

\subsection{Environmental Turbulence}

Environmental turbulence has been central in both driving and delaying the EGD. As noted, the green wave across Europe and especially in the Parliament had considerable effects and von der Leyen made different promises to multiple EU political parties reflected in ambitious political guidelines and the EGD (von der Leyen, 2019). Whilst the manifold, eclectic promises may create further challenges (see "Policy Turbulence" in Sub-Section 4.3), the existing turbulence was the impetus for an innovative, highly ambitious (at times) policy. Beyond the Parliament, growing pressure from activists-Greta Thunberg and the Fridays for Future 
climate marches-and their willingness to both engage and publicly criticise the EU for inaction, has the potential to take key policy debates about the EGD beyond the Brussels bubble and spur ambition.

But environmental turbulence has also hampered EGD development. Repeated delays on the Brexit negotiations pushed back Commission approval and delayed the launch of the EGD, before Covid-19 temporarily derailed all political plans-impacting on lives, economies, political relationships, and political priorities. Although public health, the environment, and the economy are clearly interlinked and dependent on each other in the long-term, they have been portrayed as a dichotomy (Georgieva \& Adhanom Ghebreyesus, 2020). Adopting yet again such a dichotomic approach regarding Covid-19 vis-à-vis other focuses, including the EGD, forces black and white choices upon the public and decision-makers rather than finding positive, beneficial solutions towards a green recovery such as developing green jobs or nature-based solutions to environmental problems and pollution (WWF, 2020). The nature of this false dichotomy was eventually recognised by the EU (Dupont et al., 2020), which arguably utilised this specific ongoing turbulence to help further the EGD by shifting the focus to a green recovery.

Euroscepticism within and beyond the EU is undermining the chances of the EGD to attain its full potential. Externally, Brexit is dampening the moods on both sides of the Channel, where the issue around a level playing field in environmental, food, and animal welfare standards proved one of the pinch points for the EU/UK Trade and Cooperation Agreement. Internally, Eurosceptic member of the Parliament tend to reject climate and energy policies, and the Visegrád group (Poland, Hungary, Czechia, and Slovakia) frequently calls for less ambition to avoid carbon leakage (businesses moving away from the EU to countries with laxer climate policies) and impacts on competitiveness (Zapletalová \& Komínková, 2020). While this is not new, it is becoming more consequential. After years of environment and climate action being side-lined at the EU level (Čavoški, 2015), and thus this sharp East/West divide happening in an area of relatively low political salience, it is now the flagship policy issue for a Commission whose (as of yet limited) efforts on rule of law put it in direct confrontation with Poland and Hungary.

\subsection{Policy Turbulence}

Mainstreaming is one of three procedural themes of the EGD-both an old debate at the EU level (treaty commitments to environmental policy integration date back to the 1980s) and still very much a live issue. The last 20 years saw a narrowing down of environmental policy integration into climate policy integration-for example the EU's previous long-term strategy's (Europe 2020, adopted in 2010) environmental objective of sustainable growth largely had a climate and energy focus, omit- ting most environmental issues (Steurer, 2021). The EGD adopts a much wider scope on environmental policy integration and brings back to the top of the EU agenda both broad environmental issues (including biodiversity) and other policy areas (agriculture), which had been peripheral to EU long-term strategies (Lisbon and Europe 2020 Strategies) and either forgotten or inured from the type of changes required of other policy areas. The EGD gives teeth to mainstreaming-both through its "fit for 55" agenda of evaluating existing legislation (whether they are fit to support the EU in reaching its 2030 target) and in one other of the EGD seven substantive themes, explicitly focused on greening the CAP. But the 2021 CAP reform demonstrates that these teeth are not sharp enough. The von der Leyen Commission introduced the EGD without removing and rewriting the CAP reform proposal produced under the Juncker Commission, arguing that it could be coherent with the EGD if the legislators not only maintained, but raised its ambition. However, environmental ambition in CAP reforms tends to be reduced, not increased by both the Parliament and the Council (Gravey \& Buzogány, 2021), and 2021's trilogue confirms this trend. Thus, while in December 2019 it appeared that the EGD could potentially disrupt (at least from an environmental/sustainability perspective) the CAP reform process, the opposite has unfolded with the Council weakening CAP greening ambitions and widening the gap between the CAP and the EGD (Fortuna \& Foote, 2021).

\subsection{Scalar Turbulence}

Scalar turbulence, beyond those sources that overlap with environmental turbulence, remains largely in waiting to-date and will most likely manifest when it comes to the gradual implementation of the EGD and related policies, due to the roles of the $\mathrm{EU}$ and the member states. Many of the areas integral to the EGD, including the environment and agriculture, are shared competences between the EU and the member states. Interestingly, in the next CAP increased responsibility will be placed on the member states to deliver the goals of the EGD. The partial repatriation of the CAP could lead to greater intra-EU divergence, fuelling both horizontal and vertical turbulence as less ambitious member states undermine their more ambitious neighbours (Matthews, 2021). Such repatriation may nevertheless provide an opportunity for the Commission to green the CAP a posteriori: All new National Strategic Plans for disbursing CAP funding will need to be graded against EGD commitments as part of approval process by the Commission.

\subsection{Confirming the Transversal Character of Turbulence}

These four forms of turbulence interact demonstrating the transversal nature of turbulence: e.g., CAP funding is used to support friends and leaders of member states experiencing democratic backsliding-from Czech 
President Babis being one of Czechia's biggest CAP recipients creating a conflict of interest (Wanat, 2020), to the links between CAP funding and regime allies in Hungary uncovered by New York Times journalists (Gebrekidan et al., 2019). This reflects what Kelemen calls the EU's "autocracy trap," whereby EU funding with few strings attached is used to strengthen its opponents (Kelemen, 2020, p. 481). In challenging the CAP, the EGD therefore not only creates policy turbulence, it challenges this autocracy trap and contributes to organisational and environmental turbulence.

\section{Governing the EGD Through Turbulence: An Assessment of Difficult Choices}

Identification of turbulence is only half the battle. The EU must now seek to respond to turbulence to avoid the obstacles it poses and take advantage of the opportunities it provides. Returning to the framework, this begs two questions: first, whether there are appropriate tools and pathways open to the EU; and second, whether the European Commission is availing of these in a robust and holistic manner to deliver transformative change.

On the first, a multitude of pathways exists in the EU, whether at the EU level or internally within the member states. For instance, soft law (e.g., guidance documents and policy papers) may be availed of in lieu of hard law (Eliantonio et al., 2021); funding with conditions may be offered as an incentive, rather than creating prohibitions with associated penalties; public-private agreements may be developed; networks may be cultivated; corporate social responsibility may be supported; and policies may be either centralised or de-centralised. A wide range of "new environmental policy instruments" exists within the EU (Moore et al., 2021). However, the availability of measures does not guarantee their suitability or uptake in a manner to achieve governance with turbulence.

On the second, the EGD is a good first step, as it takes innovative approaches and could be truly transformative. However, its development and implementation must continue to be transformative to address ongoing turbulence and it must do so in a more holistic manner. Unfortunately, the EU appears to have fallen into the pitfall of siloed approaches; while the EGD has a very wide scope, it will be delivered through a number of strategies, some of which are narrow in scope (e.g., greening the CAP, the Farm to Fork Strategy, and the Biodiversity Strategy) and may drift further apart through the legislative process (as the CAP and the Farm to Fork Strategy are currently doing). Further, and linked at times to siloed approaches, the EU has made policy decisions that have entailed various forms of prioritisation with significant consequences as demonstrated in Sub-Section 5.1.

\subsection{Prioritisation in Practice}

Prioritisation rests on a gamble that the problem created or left by the chosen solution is smaller and eas- ier to tackle than the original problem. Examples include (1) the prioritisation of one area over another and addressing policy turbulence over scalar turbulence in the context of the CAP; $(2)$ the prioritisation of functions over agenda in responding to Covid-19; and (3) the prioritisation of functions and agenda over values in agreeing the Next Generation EU and 2021-2027 Multiannual Financial Framework plans in the Council.

The first example highlights the potential consequences of both prioritising one area (the CAP) over another (Farm to Fork, and the EGD more generally) and addressing one form of turbulence (policy) over another (scalar). Greening the CAP has until now yielded few environmental gains, with soil degradation, habitats loss, and water pollution continuing (Alons, 2017; European Environment Agency, 2020). The proposed use of National Strategic Plans in the new CAP, with a repatriation of policy development, can be seen as the use of an alternative pathway (repatriation) to allow at least some member states to further green their farming sector. In pursuing such an approach, the EU (and in particular the Commission) is trying to avoid being (yet again) scapegoated for policy failure. However, it is effectively shifting responsibility (Fouilleux \& Gravey, in press), and delegating the task of ensuring that the new CAP strengthens the Farm to Fork initiative and overall EGD to national governments - thereby also risking its failure.

Thus, that the Council is pushing for lowering the threshold of CAP payments ring-fenced for environment and climate action is not encouraging on its own (Fortuna \& Foote, 2021) but also due to what it means for the likely success of two other EGD strategies, the Farm to Fork and Biodiversity Strategies. The Farm to Fork strategy focuses on a holistic approach towards the sustainability of food systems with an emphasis on sustainable food production, sustainable food consumption, food loss and waste prevention, as well as sustainable food processing and distribution. A key aspect of the Strategy includes the reduction by 2030 of the use of more hazardous pesticides by $50 \%$ (European Commission, 2021). However, this ambitious target will be difficult to meet, as the French experience of Ecophyto illustrates. Created in 2008, the Ecophyto plans set high ambitious regulatory targets for pesticides reduction. However, they were running alongside a CAP whose payments were pushing farmers in another direction and France repeatedly failed to meet its targets, with pesticide use increasing instead (Petetin et al., 2019). Ecophyto failures illustrate the central role of the CAP in changing farming practices and how the future CAP could undermine the whole landuse and biodiversity sections of the EGD. Whether the Commission, when negotiating one-on-one with each member state on their plans, manages to deliver better EGD complementarity remains to be seen. Critically, the new CAP therefore risks fuelling scalar turbulence, both vertically between the member states and the EU, if the Commission strictly polices the content of these national plans, and horizontally between member states 
opting for very different levels of ambition leading to a more uneven level playing field across the EU. It also risks increasing policy turbulence for the EGD, through creating internal conflicts.

The second example of prioritisation-relating to potential conflicts between policy agendas and functions-is exemplified by the EU response to Covid-19. The EU has limited competence in health policy-it remains with the member states. Initially, the EU was very hesitant to act regarding Covid-19, despite its impacts on the EU's policies directly and indirectly (through for instance member states' actions), including on the free movement of goods and persons - respecting the functions over the public agenda (Purnhagen et al., 2020). It limited itself to actions such as the public procurement of personal protection and other medical equipment. However, over time, the continuing turbulence and knock-on impacts motivated the EU to further action, through proposing EU-wide approaches to exiting lockdowns, travel restrictions, funding, and vaccines. Nonetheless, in doing so, the EU has attempted to restrict itself to either unanimous decisions or soft measures, thereby still respecting its overall functions. A concern would be that the EU would overly restrict itself in developing and implementing the EGD, e.g., due to it being an area of shared competence and not exclusive EU competence, or through seeking to appease member states or other EU institutions.

A third example of prioritisation - this time delivering a policy agenda and functions over values-is the budget compromise negotiated by the German presidency of the Council in December 2020. Hungary and Poland accepted to withdraw their veto to the new budgetary package (Multiannual Financial Framework 2021-2027 and Next Generation EU) as long as the new rule of law mechanisms, which would enable the suspension of disbursement of EU funds in case of corruption or other failures to meet rule of law criteria, would not be used until Hungary and Poland have had the opportunity to challenge the rule in front of the Court of Justice of the EU and get a verdict (Bayer, 2020). This pushes back the actual application of the rule of law mechanism, perhaps for years-as the Hungarian and Polish governments can first take their time to start the annulment procedure and second because the Court of Justice is not renowned for its swiftness. This compromise prioritised getting the budget through and financing the EU's post-Covid recovery over standing up for the rule of law-echoing earlier choices of the EU to de-prioritise the rule of law and human rights (Kelemen, 2020).

Whether these gambles will pay off remains unclear. Prioritisation is a normal component of policymaking, but turbulence exacerbates the situation-uncertainty pervades, numerous issues need to be addressed simultaneously, and responses may create further turbulence or not bring the expected outcomes. Irrespective of results, for the EGD to be truly transformative, a more holistic, robust response should be taken where possi- ble and these choices should be open for political debate and require clear justification.

\section{Conclusions}

The world is becoming increasingly turbulent, exemplified within the EU today by the accumulation of events such as Brexit, the Covid-19 pandemic, the Green Wave, conflicts over the rule of law, and significant policy overhauls including the ongoing reform of the CAP and the EGD itself. The EGD is simultaneously a source of and response to turbulence but crucially, for the purposes of this article and thematic issue, also operates within a context of turbulence.

This article built upon the work of Ansell and co-authors $(2016,2018,2020)$ to develop an enhanced conceptual framework. Ansell et al. initially identified three central forms of turbulence: organisational, environmental, and scalar. This article broadened scalar turbulence to encompass also horizontal turbulence (alongside vertical turbulence). It also demonstrated the existence of a fourth form of turbulence-policy turbulence-reflected in the introduction of fundamentally new policies such as the EGD, or the inherent conflict between policies or prongs of an individual policy such as with the CAP. It further expanded Ansell and Trondal's (2018) reflection on the connections between turbulence at different levels, showing how turbulence can be transversal-different forms of turbulence, and responses to these, fuel new forms of turbulence.

This article developed a conceptual framework for this thematic issue by operationalizing what turbulence means for delivering and implementing the EGD and the challenges policy actors, notably the Commission, face in governing with and not against turbulence. Turbulence brings new challenges and opportunities, as it forces actors to look beyond the status quo and think outside the box. If the Commission and other actors seeking to implement the EGD simply continue as normal, then the deal risks stalling and being undermined, for example through being derailed by Covid-19, blocked by Hungary and Poland, weakened by the failing legitimacy of the EU or the Commission, or pushed down the priority list by future incidents. Responses to turbulence, including prioritization, may increase turbulence and lead to undesirable outcomes. On the other hand, the EGD itself demonstrates the potential for turbulence to help instigate, develop, and implement innovative and future-facing policies. To achieve this, policy actors must acknowledge and address the turbulence they face; they must learn to govern with turbulence and, to this end, undertake transformative actions in a holistic manner.

Overall, the article highlighted the significance of governing with turbulence, the need for durability and robustness, and key concerns in operationalizing this. Great care is needed by policy actors in identifying the sources of turbulence, their impacts, and what mechanisms or pathways might enable them to steer a way to 
a robust response. This does not necessitate the eradication of all turbulence-turbulence is not an "evil" in and of itself-but simply reflective thinking to see how best to respond. Ansell and co-authors $(2016,2018)$ discussed how a "good" decision for a level could be "bad" for another. Our exploration of turbulence and the EGD revealed a murkier picture, where EU decisionmakers struggle to identify any universally "good" decisions. Eschewing the arguably high bar of transformative, holistic responses to turbulence, EU leaders make problematic gambles-for instance hard decisions are passed to lower levels of governance, or, as with the rule of law mechanism, further delayed.

\section{Acknowledgments}

The authors would like to thank Claire Dupont and Diarmuid Torney for leading this thematic issue and providing expert guidance; participants of the workshop for their feedback and the three anonymous reviewers for their useful comments; and Daniel Lynch for advice on the last version.

\section{Conflict of Interests}

The authors declare no conflict of interests.

\section{References}

Alons, G. (2017). Environmental policy integration in the EU's common agricultural policy: Greening or greenwashing? Journal of European Public Policy, 24(11), 1604-1622. https://doi.org/10.1080/ 13501763.2017.1334085

Ansell, C. K., Sørensen, E., \& Torfing, J. (2020). The Covid-19 pandemic as a game changer for public administration and leadership? The need for robust governance responses to turbulent problems. Public Management Review, 23(7), 949-960. https://doi. org/10.1080/14719037.2020.1820272

Ansell, C. K., \& Trondal, J. (2018). Governing turbulence: An organizational-institutional agenda. Perspectives on Public Management and Governance, 1(1), 43-57. https://doi.org/10.1093/ppmgov/gvx013

Ansell, C. K., Trondal, J., \& Øgård, M. (2016). Turbulent governance. In C. K. Ansell, J. Trondal, \& M. Øgård (Eds.), Governance in turbulent times (pp. 1-33). Oxford University Press.

Bayer, L. (2020, December 9). EU budget plan lets Hungary, Poland off the rule-of-law hook (for now). Politico. https://www.politico.eu/article/eu-budgetplan-lets-hungary-poland-off-the-rule-of-law-hookfor-now

Bürgin, A. (2020). The impact of Juncker's reorganization of the European Commission on the internal policy-making process: Evidence from the energy union project. Public Administration, 98(2), 378-391. https://doi.org/10.1111/padm.12388
Burns, C., Gravey, V., Jordan, A., \& Zito, A. (2019). DeEuropeanising or disengaging? EU environmental policy and Brexit. Environmental Politics, 28(2), 271-292. https://doi.org/10.1080/09644016.2019.1549774

Cameron, K. S., Kim, M. U., \& Whetten, D. A. (1987). Organizational effects of decline and turbulence. Administrative Science Quarterly, 32(2), 222-240.

Čavoški, A. (2015). A post-austerity European Commission: No role for environmental policy? Environmental Politics, 24(3), 501-505.

Dobbs, M. (2020). National governance of public health responses in a pandemic? European Journal of Risk Regulation, 11(2), 240-248. https://doi.org/ 10.1017/err.2020.39

Dobbs, M., Gravey, V., \& Petetin, L. (2021). The turbulent development of agricultural policies post-Brexit. CELTS Online Paper Series, 9(1), 1-17. https://www. qub.ac.uk/research-centres/centre-europeantransnational-studies/FileStore/Filetoupload, 1129237,en.pdf

Dupont, C., Oberthür, S., \& von Homeyer, I. (2020). The Covid-19 crisis: A critical juncture for EU climate policy development? Journal of European Integration, 42(8), 1095-1110. https://doi.org/10.1080/ 07036337.2020 .1853117

Eliantonio, M., Korkea-aho, E., \& Stefan, O. (Eds.). (2021). EU soft law in member states: Theoretical findings and empirical evidence. Hart Publishing.

European Commission. (2017). Special eurobarometer 468: Attitudes of European citizens towards the environment [Data set]. data.europa.eu. https:// data.europa.eu/euodp/en/data/dataset/S2156_88_ 1_468_ENG

European Commission. (2019a). Annex to the European Green Deal. https://eur-lex.europa.eu/legalcontent/EN/TXT/PDF/?uri=CELEX:52019DC0640\& from $=\mathrm{EN}$

European Commission. (2019b). The European Green Deal (COM(2019) 640 final). https://ec.europa.eu/ info/sites/info/files/european-green-dealcommunication_en.pdf

European Commission. (2021). Farm to fork strategy. https://ec.europa.eu/food/horizontal-topics/farmfork-strategy_en

European Environment Agency. (2020). The European environment: State and outlook 2020-Knowledge for transition to a sustainable Europe. https://www. eea.europa.eu/soer-2020

Falkner, G. (2016). The EU's current crisis and its policy effects: Research design and comparative findings. Journal of European Integration, 38(3), 219-235.

Fortuna, G., \& Foote, N. (2021, May 28). CAP talks crash on the "floor" amid interinstitutional blame game. Euractiv. https://www.euractiv.com/section/ agriculture-food/news/cap-talks-crash-on-thefloor-amid-interinstitutional-blame-game

Fouilleux, E., \& Gravey, V. (in press). The common agricultural policy. In M. Cini \& N. Pérez-Solorzano Borragan 
(Eds.), European Union politics (7th ed.). Oxford University Press.

Gebrekidan, S., Apuzzo, M., \& Novak, B. (2019, November 3). The money farmers: How oligarchs and populists milk the EU for millions. The New York Times. https://www.nytimes.com/2019/11/03/world/ europe/eu-farm-subsidy-hungary.html

Georgieva, K., \& Adhanom Ghebreyesus, T. (2020, April 3). Some say there is a trade-off: Save lives or save jobs-This is a false dilemma. The Telegraph. https://www.telegraph.co.uk/global-health/scienceand-disease/protecting-healthandlivelihoods-gohand-in-hand-cannot-save

Gravey, V., \& Buzogány, A. (2021). For farmers or the environment? The European Parliament in the 2013 CAP reform. Politics and Governance, 9(3), 16-28.

Guiso, L., Sapienza, P., \& Zingales, L. (2014). Monnet's error? London School of Economics.

Hennessy, A. (2019, July 17). Ursula von der Leyen: Why controversial choice for EU top job may actually have been the right one. The Conversation. https://theconversation.com/ursula-von-der-leyenwhy-controversial-choice-for-eu-top-job-mayactually-have-been-the-right-one-120511

Hooghe, L., \& Marks, G. (2003). Unraveling the central state, but how? Types of multi-level governance (Working Paper No. 87). IHS Political Science Series.

Jordan, A., \& Moore, B. (2020). Durable by design? Policy feedback in a changing climate. Cambridge University Press.

Kassim, H., Peterson, J., Bauer, M. W., Connolly, S., Dehousse, R., Hooghe, L., \& Thompson, A. (2013). The European Commission of the twenty-first century. Oxford University Press.

Kelemen, R. D. (2020). The European Union's authoritarian equilibrium. Journal of European Public Policy, 27(3), 481-499. https://doi.org/10.1080/13501763. 2020.1712455

Klyza, C., \& Sousa, D. (2013). American environmental policy beyond gridlock (2nd ed.). MIT Press.

Laffan, B., O'Donnell, R., \& Smith, M. (2000). Europe's experimental union. Routledge.

Matthews, A. (2021, February 26). Improving governance of the future CAP. Cap Reform. http:// capreform.eu/improving-governance-of-the-futurecap

Moore, B., Benson, D., Jordan, A., Wurzel, R. K. W., \& Zito, A. (2021). Governing with multiple policy instruments? In A. Jordan \& V. Gravey (Eds.), Environmental policy in the EU actors, institutions, and processes (pp. 299-316). Routledge.

Oberthür, S., Görlach, B., Bart, I., Księżopolski, K., Barata, P., \& Nesbit, M. (2016). The EU in turbulence: What are the implications for EU climate and energy policy? Ecologic. http://ecologic.eu/14129
Oberthür, S., \& Stokke, O. S. (2011). Institutional interaction in global environmental change. In S. Oberthür \& O. S. Stokke (Eds.), Managing institutional complexity: Regime interplay and global environmental change (pp. 1-23). MIT Press.

Petetin, L., Gravey, V., \& Moore, B. (2019). Green Brexit: Setting the bar for a green Brexit in food and farming. The Soil Association. https://www.brexit environment.co.uk/wp-content/uploads/dlm_ uploads/2019/06/SoilAssociationFull.pdf

Purnhagen, K. P., de Ruijter, A., Flear, M. L., Hervey, T. K., \& Herwig, A. (2020). More competences than you knew? The web of health competence for European Union action in response to the Covid-19 outbreak. European Journal of Risk Regulation, 11(2), 297-306. https://doi.org/10.1017/err.2020.35

Rhinard, M. (2019). The crisisification of policy-making in the European Union. Journal of Common Market Studies, 57(3), 616-633. https://doi.org/10.1111/ jcms. 12838

Saurugger, S. (2014). Europeanisation in times of crisis. Political Studies Review, 12(2), 181-192. https://doi. org/10.1111/1478-9302.12052

Steurer, R. (2021). Is the EU still committed to developing more sustainably? In A. Jordan \& V. Gravey (Eds.), Environmental policy in the EU actors, institutions, and processes (pp. 279-298). Routledge.

von der Leyen, U. (2019). A Union that strives for more: My agenda for Europe. Political guidelines for the next European Commission 2019-2024. European Parliament. https://www.europarl.europa.eu/ resources/library/media/20190716RES57231/ 20190716RES57231.pdf

Votewatch Europe. (2021, March 3). Impact of EPP-Fidesz divorce to be bigger than expected. https://www.votewatch.eu/blog/impact-of-eppfidesz-divorce-to-be-bigger-than-expected

Wanat, Z. (2020, December 7). Czech PM Babiš faces long road after EU audit. Politico. https://www. politico.eu/article/commission-audit-spells-longroad-ahead-for-czech-pm-babis

WWF. (2020). Nature hires: How nature-based solutions can power a green jobs recovery. https:// wwfint.awsassets.panda.org/downloads/nature_ hires_report_wwf_ilo.pdf

Yun, S., Lee, J., \& Lee, S. (2019). Technology development strategies and policy support for the solar energy industry under technological turbulence. Energy Policy, 124, 206-214. https://doi.org/10.1016/j.enpol. 2018.09.003

Zapletalová, V., \& Komínková, M. (2020). Who is fighting against the EU's energy and climate policy in the European Parliament? The contribution of the Visegrad Group. Energy Policy, 139. https://doi.org/10.1016/ j.enpol.2020.111326 


\section{About the Authors}

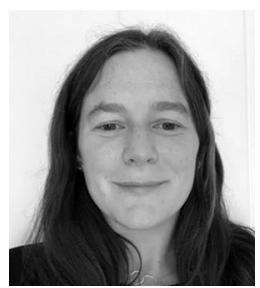

Mary Dobbs is a lecturer in the Department of Law in Maynooth University, Ireland. She previously worked in Queen's University Belfast and remains a visiting fellow in the School of Law there. She specialises in environmental law and governance, especially regarding Brexit, environmental principles, agriculture, and genetically modified crops.

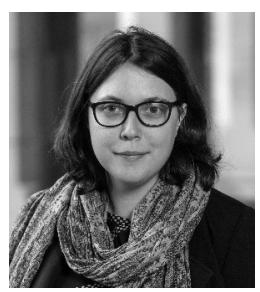

Viviane Gravey is a lecturer in European politics at the School of History, Anthropology, Philosophy, and Politics at Queen's University Belfast, where she co-chairs the Brexit \& Environment network, investigating the impact of Brexit on the UK and EU environment. She holds a PhD from the University of East Anglia. Her research focuses on the ambition and governance of environmental and agricultural policies in the UK and at EU level.

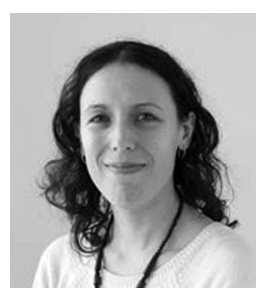

Ludivine Petetin is a senior lecturer in law at the School of Law and Politics of Cardiff University. Her expertise lies in agri-environmental-food issues and international trade as well as the challenges that Brexit and Covid-19 pose to these areas. She regularly engages with governments, legislatures, and stakeholders across the UK on these matters. 